\title{
ROLE OF MEDICINAL PLANT EXTRACTS IN ERADICATION OF MULTI DRUG RESISTANT MICROBES
}

\author{
Smruti Mahapatra \\ Department of Biotechnology, \\ School of Biosciences and Technology, \\ Vellore Institute of Technology, Vellore, \\ Tamilnadu, India
}

\author{
Pratyush Kumar Das \\ Department of Training \& Innovation \\ Heredity Life Sciences, Bhubaneswar, \\ Odisha, India
}

\author{
Swadhin Palo \\ Department of Training \& Innovation \\ Heredity Life Sciences, Bhubaneswar, \\ Odisha, India
}

\begin{abstract}
The Indian Ayurvedic medicine is a classical medicinal method that has a rich history and solid foundation. Herbal medicines play a significant role in the prevention and management of human diseases. For millennia, plants have been used as folk medicine. Medicinal plants are an abundant source of the secondary metabolite formed by plants, the bioactive phytochemicals. Scientific studies in recent decades have demonstrated the significant role of these phytochemicals in the prevention of infectious disease. In recent decades, the re-discovery of medicative plants as a source of potential therapies has become a great deal of interest. Plant-based product lines can regulate microbial development in different scenarios. The worldwide danger to public health arose from the resistance among distinct microbial species to multiple antimicrobial drugs. Approximately every competent infective agent has high levels of multi drug resistance with strengthened morbidity \& mortality, which makes them called 'superbugs.' Only by designing entirely new methods, the multi-drug resistance crisis can be tackled. The goal of this study is true to clarify the information of medicinal herbs as a potential basis for herbal supplements against microbes with multi-drug resistance.
\end{abstract}

Keywords- Disease, Microbes, Multi drug Resistant (MDR), Phytochemicals, Plant extracts.

\section{INTRODUCTION}

Introduction and progression of the human and animal infectious disease involve 3D interactions between the infectious bacterial strains, atmosphere, and immune state of an organism [1]. The effectiveness of currently available antibiotics is under attack as multidrug-resistant (MDR) pathogens emerge [2]. Scientists are concentrating more and more on medicinal herbs and it is reported that $25-50 \%$ of Western medicines include or have supplied plant materials in them [3]. Numerous currently accessible modern medicines were originally utilized for folk medicines in the crude form [3]. Plants manufacture a wide range of fine compounds, they are known as phytoalexins, which were meant to be essential for protecting plants. Phytoalexins are structurally functional and are expected to have antimicrobial activities [4] because they include terpenoids, Polyphenols, glycosteroids, and flavonoids. Most of the seasonings used among human beings in the preparation of the food contain valuable pharmaceutical compounds [5]. It is approximated that there are at least 0.2 million bioactive compounds formed by the species of plants sprouting on Earth, but it represents just a fraction of them [6]. Per year, there are nearly 0.44 million new cases of MDR-TB, triggering around 0.15 million deaths worldwide [7]. Through the latest years, scientific interests in pharmaceutical plant species have been improved. Furthermore, the battle against such rapid advancement of pathogens requires the introduction of novel and unique antibiotics. Throughout the last two decades, the implementation of novel antibiotics has steadily 
declined, making such drug-resistant pathogens difficult to treat [8]. Confronted with these kinds of complexity and obstacles, the exploration for new antimicrobial substances or plant-based metabolites with a wide range of function and immunomodulatory reaction towards pathogenic microbial strains is desperately crucial.

The current review highlights the current burning issue of increasing resistance of antimicrobials among microorganisms. The mechanism behind antimicrobial resistance by multi drug resistant microbes has been explained in brief. The current study also discusses and supports the role of phytochemicals in eradication of these microbes thereby preventing several diseases and improving the quality of human health.

\section{ANTIMICROBIAL RESISTANCE AND ITS MECHANISMS}

Microbes can develop tolerance to a variety of antimicrobial agents through various mechanisms (Figure 1). These mechanisms include inactivation of antibiotics, modification of target sites, efflux of antimicrobials, and plasmidic resistance.

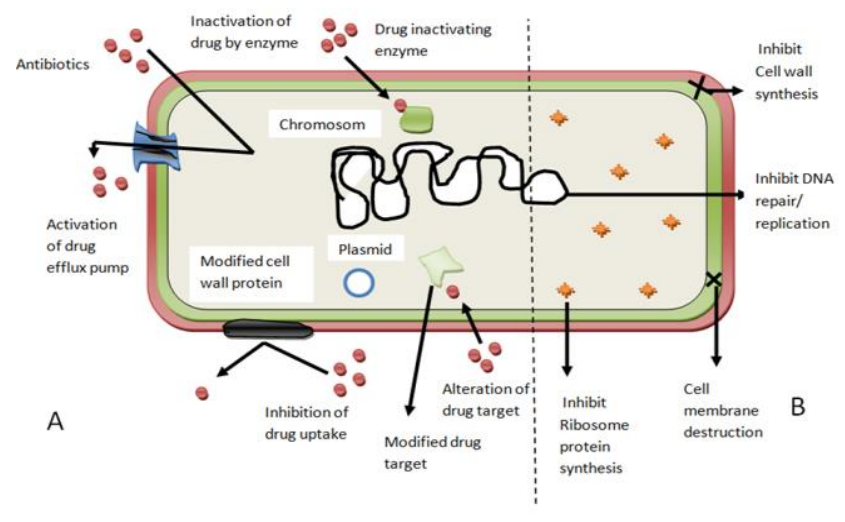

Fig.1. (A) Different mechanism of development of antibiotic resistance; (B) Different mechanism of antibiotic actions

\section{A. Antibiotic Inactivation-}

Few bacteria have been immune against $\beta$-lactam antibiotics by altering the antibiotics or by releasing a range of enzymes including transfers that prevent or disturb the chemical properties of antibiotics [9]. Plasmids are just bacterial extrachromosomal substance genomic sequences encoding resistance to certain antibiotic forms. The development of $\beta$ lactamase-enzymes leads to the destruction of the $B$ lactam ring by affecting the amide bond. Hence, mostly ineffective on $\beta$-lactam-containing antibacterial drugs like ampicillin, penicillin, piperacillin, imipenem, ceftazidime, etc [10].

\section{$B$. Target Modification-}

Antimicrobials work at a specific location where those interact and modify the usual mechanism; space is named target site. Contributing to variations in these specific areas, the microorganisms are immune to certain antibiotics. Changing or altering the target site can be the product of bacterialgenerated enzymes.

\section{Efflux Mechanism of Resistance-}

Efflux pumping protein-encoding genes required for the management of cellular function [11] activates the underlying antibiotic resistance in microbial communities. Many effluxmechanisms in microbes are not drug-specific molecules that recognize or dispose of chemicals, antimicrobials, and structurally not related substances without modifications or deterioration of the drug. Deportation of these antibiotics or compounds out of the cells leads to decreased levels of antibiotics, which have little or no effects on bacterial development.

\section{$D$. Plasmidic Resistance-}

Efflux pumping protein-encoding genes required for the management of cellular function [11] activates the underlying antibiotic resistance in microbial communities. Many effluxmechanisms in microbes are not drug-specific molecules that recognize or dispose of chemicals, antimicrobials, and structurally not related substances without modifications or deterioration of the drug. Deportation of these antibiotics or compounds out of the cells leads to decreased levels of antibiotics, which have little or no effects on bacterial development.

\section{PHYTOCHEMICALS AND THEIR PROPERTIES}

Phytochemicals are a major constituent of all the plants which demonstrate anti-microbial activity to a certain degree. These phytochemicals also naturally help the plants to protect themselves against stress conditions, pathogenic organisms, and diseases. The phytochemicals have been grouped into several types among which alkaloids, phytosterols, polyphenols, terpenoids, and organosulfur compounds are the important ones (Figure 2). 


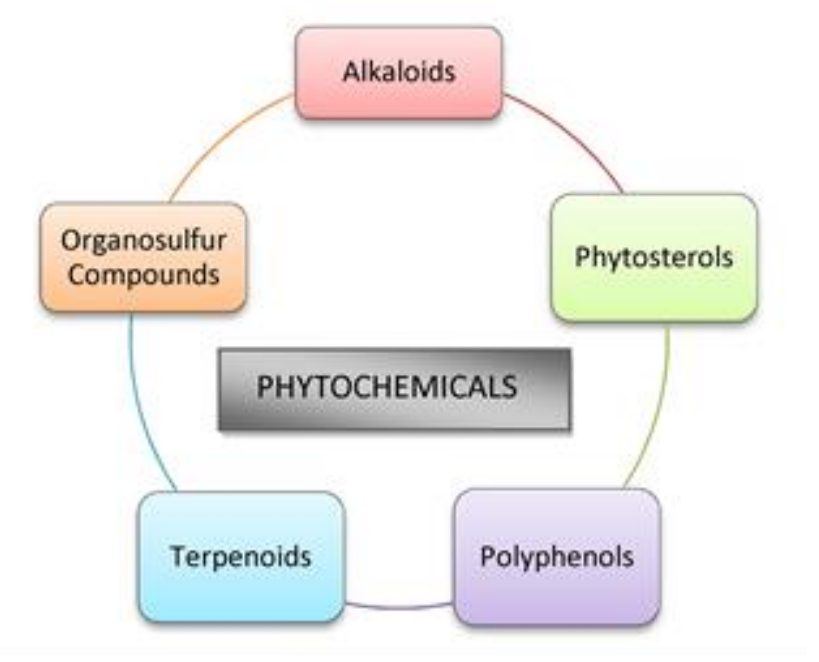

Fig.2. Important groups of phytochemicals

\section{A. Alkaloids -}

The majority of alkaloids include oxygen in their molecular composition; these are generally colorless solid crystals. Oxygen-free alkaloids, for instance, nicotine, are usually volatile, colorless and sticky fluids, and other alkaloids, for instance, berberine (yellow) and sanguinarine (orange), are colored. Alkaloid-containing herbal medicinal utilization does have a strong legacy and hence quickly finds utilization in medical care since the very first alkaloids became detected in the nineteenth century. For medications, still, several alkaloids are being used, typically as salts, which include atropine, caffeine, codeine, colchicines, etc. Many synthetic and semisynthetic medications are systemic improvements of the alkaloids; these improvements are intended to improve or alter the drug's primary action and minimize disadvantages. For reference, naloxone, a baine substitute found in opium, is an opioid receptor antagonist [12].

\section{B. Phytosterols -}

Numerous experiments have analyzed the biochemical effects of phytosterols on both animals and humans. Phytosterols also play an important role in manufacturing pharmaceutical drugs, supplements, and beauty products. Owing to the beneficial properties, these are commonly used as value-added ingredients in the nutrition and beauty industries [13]. Other fitness effects have been identified, including antifungals, antioxidants, anti-inflammatory, and antibiotic activity. Phytosterols have a reducing function in cholesterol level, anti-cancer activity and antiinflammatory activities, anti-polymerization processes, anti-atherosclerotic activity, and anti-microbial activity.

\section{Polyphenols -}

The key non-flavonoid classes include first phenolic acids which can be categorized inTO benzoic acid derivatives such as gallic acid and protocatechuic acid and cinnamic acid compounds, consisting mainly of coumaric, caffeic, and ferulic acid, second stilbenes with resveratrol as the primary constituent in both cis and trans isomeric forms and third lignans, formed by oxidative dimerization of two phenylpropane units. Besides, a broad variety of microorganisms have been investigated thoroughly with the antimicrobial activities of polyphenols in vegetable foods and medicinal plants. Polyphenols, flavan-3-ols, flavonols, and tannins have gained the utmost focus because of their vast range, stronger antimicrobial activity than others, and the reason that many of them can block and disclose many aspects of microbial virulence such as biofilm formation inhibition, host ligands adhesion reduction and bacterial toxin neutralization [14].

\section{Terpenoids -}

Terpenoid substances are derived from a specific C5 isoprene unit structure. These are categorized as per their count of isoprene groups, namely monoterpenoids (C10), sesquiterpenoids (C15), diterpenes (C20), sesterpenenes (C25), and triterpenes. They are classified according to their number (C30). They are present primarily in plants and constitute the principal component of plant essential oils. In traditional folk medicine, such terpenes were commonly used. One of the Terpenes is curcumin, which has anti-inflammatory, antioxidant, anticancer, antiseptic, astringent, astringent, diuretic, and many more other activities. Curcumin has also been the new trend In safe diets and it also has so many applications in medical science studies [15].

\section{E. Organosulfur compound -}

Many of the active components or nutraceuticals extracted from plants and animals are Organosulfur Compounds (OSCs). They include sulfur atoms, which are cyclically or can cyclically be linked to a cyanate group or carbon atom. The most popular sources of OSC are broccoli, cauliflower, chocolate, Brussels, garlic, onions, beef, eggs, and fish. The most popular example of OSC gathered from various plant sources are allicin, s-allyl cysteine, sulforaphane, cysteine, sulfonylureas, methionine, and lipoic acid. There could be various kinds of OSC in various resources and different medical benefits may be correlated with these molecules. Multiple OSC has a high antioxidant function. Besides, OSC activities have been documented to have antiplatelets, immunomodulatory, fibrinolytic, antiaging, anti-inflammatory, anti-microbial, antihypertensives, antimicrobials, and antivirals [16]. 
International Journal of Engineering Applied Sciences and Technology, 2021

Vol. 6, Issue 1, ISSN No. 2455-2143, Pages 306-310

Published Online May 2021 in IJEAST (http://www.ijeast.com)

Table.1. Phytochemicals and their anti-microbial mechanism

\begin{tabular}{|c|c|c|c|c|}
\hline Phenolic acid & Phenols & $\begin{array}{l}\text { C.jejuni, Gram +ve(Strong action), } \\
\text { Gram-ve (week action; depends on } \\
\text { strain of bacteria) }\end{array}$ & Attack on outer membrane & .[17] \\
\hline $\begin{array}{l}\text { Allicin, } \quad \text { Ajoenes, } \\
\text { Dially polysulfides }\end{array}$ & $\begin{array}{l}\text { Organi } \\
\text { sulphur } \\
\text { compounds }\end{array}$ & $\begin{array}{l}\text { Gram +ve, Gram -ve \& MDR } \\
\text { Bacteria }\end{array}$ & Inhibit Biofilm formation & {$[18]$} \\
\hline Berberine & Alkaloid & S.aureus(MRSA), M.aeruginisa & $\begin{array}{l}\text { Inhibit biofilm formation, inhibit } \\
\text { microbial amyloid formation }\end{array}$ & [19]. \\
\hline Caffeic acid & $\begin{array}{l}\text {,Phenolic } \\
\text { Compound }\end{array}$ & $\begin{array}{lrcc}\text { S. aureus, } & S . & \text { epidermidis, } & K . \\
\text { pneumoniae, } & S . & \text { marcescens, } & P . \\
\text { mirabilis, E. coli, } & \text { P. aeruginosa, } & B . \\
\text { cereus, } \quad \text { M. } & \text { luteus, } & L . \\
\text { monocytogenes } & & \end{array}$ & Membrane function impairment & [20] \\
\hline Capsaicin & Flavonoid & $\begin{array}{l}\text { S.typhimurium,P.aeruginosa, } \\
\text { E.coli, S.aureus, H.pylori, } \\
\text { V.cholera, B.subtilis }\end{array}$ & $\begin{array}{l}\text { By changing membrane fluidity } \\
\text { and efflux pump inhibition }\end{array}$ & [21] \\
\hline Curcumin & Phenol & $\begin{array}{lr}\text { S.aureus, } & \text { P.aeruginosa, } \\
\text { S.epidermidis, } & \text { S.pyogenes, } \\
\text { M.tetragenus, } & \text { M.luteus, A.faecalis } \\
\end{array}$ & $\begin{array}{lcc}\begin{array}{l}\text { Antibiofilm } \\
\text { inhibiting quorum sensing }\end{array} & \text { by }\end{array}$ & [22]. \\
\hline Eugenol & Phenol & $\begin{array}{l}\text { Bacillus subtilis, Clostridium } \\
\text { sporogenes, Enterococcus faecalis, } \\
\text { Lactobacillus plantarum, Listeria } \\
\text { monocytogenes, Escherichia coli } \\
\text { and Salmonella pullorum }\end{array}$ & $\begin{array}{l}\text { Alteration of membrane fatty } \\
\text { acids, Changes in cell } \\
\text { morphology and disruption of } \\
\text { cytoplasmatic membrane, } \\
\text { Production of intracellular ROS, } \\
\text { Inhibition of some bacterial } \\
\text { enzymes }\end{array}$ & {$[23,24]$} \\
\hline
\end{tabular}

\section{CONCLUSION}

In medical sciences, alternative drugs, like herbs, have arisen as a blessing as they are widely available and have virtually no side effects. For most of the countries with rich plant diversity, marking and isolating phytochemical components from plants remains a problem. A bacterial infection is a normal feature of the lives of both humans and animals. In the current situation, the use of numerous herbs and herbal medicine is both healthy and affordable. The appearance of MDR microbes and decreasing effectiveness of conventional antibiotics has prompted scientists to rethink about the ancient curing approaches. The use of herbal medicine products has been generally recognized and is likely to remain focused on conventional remedies for their essential health care for nearly 80 percent of the world population. Plants have a complex role in managing bacterial infections with antibiotic resistance. Consequently, a detailed analysis is required to understand different phytochemicals. Many of these phytochemicals are biologically quite active and hazardous but they need to be closely checked. The phytochemical behaviour of every phytoconstituents depends on the degree and existence of some other compound. Various pharmacological practices or their variations have yet to be identified for each phytoconstituents. More studies are essential to convert this information into future medicinal therapies. The precise molecular mechanism of the compound needs to be known. Moreover, it may be effective in designing a new therapeutical method to learn about the antimicrobial activities of plantderived compounds. To sum up, people have given greater attention to natural herbal goods because of their efficacy in recent times. Numerous experiments do have to be performed to guarantee the process and protection of antimicrobial phytochemicals. 


\section{REFERENCE}

[1] A. Rahal, A.H. Ahmad, A. Prakash, R. Mandil, A.T. Kumar, "Environmental attributes to respiratory diseases of small ruminants," Veterinary medicine international, Vol. 2014, 853627, 2014. https://doi.org/10.1155/2014/853627

[2] P. Dahiya, S. Purkayastha, "Phytochemical screening and antimicrobial activity of some medicinal plants against multidrug resistant bacteria from clinical isolates," Indian journal of pharmaceutical sciences. Vol. 74, Issue 5, pp. 443-450, 2012

[3] B. Thapa, A. Singh, R. Tuladhar, "In vitro Antibacterial effect of medicinal plants against multidrug resistant Gram negative bacteria," Tribhuvan University Journal of Microbiology, Vol. 26, Issue 5, pp. 25-31, 2018.

[4] N.N. Azwanida, "A review on the extraction methods use in medicinal plants, principle, strength and limitation", Med Aromat Plants. Vol. 4, Issue 3, pp. 196, 2015. Doi: 10.4172/2167-0412.1000196

[5] B.M. Kyaw, C.S. Lim, "Bactericidal antibioticphytochemical combinations against methicillin resistant Staphylococcus aureus", Brazilian Journal of Microbiology, Vol. 43, Issue 3, pp. 938-945, 2012.

[6] T. Efferth, E. Koch, "Complex interactions between phytochemicals. The multi-target therapeutic concept of phytotherapy", Current drug targets, Vol. 12, Issue 1, pp.122132, 2011

[7] A. Ghafur, 'The Chennai Declaration': An Indian perspective on the antimicrobial resistance challenge. Journal of global antimicrobial resistance. 2013 Mar 1;1(1):5-6.

[8] R. Subramani, M. Narayanasamy, K.D. Feussner, Plantderived antimicrobials to fight against multi-drug-resistant human pathogens. 3 Biotech. 2017 Jul;7(3):1-5.

[9] Viana Marques DD, Machado SE, Ebinuma VC, Duarte CD, Converti A, Porto AL. Production of $\beta$-lactamase inhibitors by Streptomyces species. Antibiotics. 2018 Sep;7(3):61.

[10] Bush K, Fisher JF. Epidemiological expansion, structural studies, and clinical challenges of new $\beta$-lactamases from gram-negative bacteria. Annual review of microbiology. 2011 Oct 13;65:455-78.

[11] Sharma A, Gupta VK, Pathania R. Efflux pump inhibitors for bacterial pathogens: From bench to bedside. The Indian journal of medical research. 2019 Feb;149(2):129.

[12] Babbar N. An introduction to alkaloids and their applications in pharmaceutical chemistry. The Pharma Innovation Journal. 2015 Dec 1;4(10):74-5.

[13] Chen XW, Sun SD, Yang GL, Ma CG. Engineering phytosterol-based oleogels for potential application as sustainable petrolatum replacement. RSC Advances. 2020;10(1):244-52.

[14] Daglia M. Polyphenols as antimicrobial agents. Current opinion in biotechnology. 2012 Apr 1;23(2):174-81.

[15] Cox-Georgian D, Ramadoss N, Dona C, Basu C. Therapeutic and medicinal uses of terpenes. InMedicinal Plants 2019 (pp. 333-359). Springer, Cham.

[16] Walag AM, Ahmed O, Jeevanandam J, Akram M, Ephraim-Emmanuel BC, Egbuna C, Semwal P, Iqbal M, Hassan S, Uba JO. Health Benefits of Organosulfur Compounds. InFunctional Foods and Nutraceuticals 2020 (pp. 445-472). Springer, Cham.

[17] Patra AK. An overview of antimicrobial properties of different classes of phytochemicals. Dietary phytochemicals and microbes. 2012:1-32

[18] Nakamoto M, Kunimura K, Suzuki JI, Kodera Y. Antimicrobial properties of hydrophobic compounds in garlic: Allicin, vinyldithiin, ajoene and diallyl polysulfides. Experimental and therapeutic medicine. 2020 Jan 31;19(2):1550-3.

[19] Chu M, Zhang MB, Liu YC, Kang JR, Chu ZY, Yin KL, Ding LY, Ding R, Xiao RX, Yin YN, Liu XY. Role of berberine in the treatment of methicillin-resistant Staphylococcus aureus infections. Scientific reports. 2016 Apr 22;6(1):1-9

[20] Kępa M, Miklasińska-Majdanik M, Wojtyczka RD, Idzik D, Korzeniowski K, Smoleń-Dzirba J, Wąsik TJ. Antimicrobial potential of caffeic acid against Staphylococcus aureus clinical strains. BioMed research international. 2018 Jul 15;2018.

[21] Kar, D., Bandyopadhyay, S., Dimri, U., Mondal, D.B., Nanda, P.K., Das, A.K., Batabyal, S., Dandapat, P. and Bandyopadhyay, S., 2016. Antibacterial effect of silver nanoparticles and capsaicin against MDR-ESBL producing Escherichia coli: an in vitro study. Asian Pacific Journal of Tropical Disease, 6(10), pp.807-810.

[22] Adamczak A, Ożarowski M, Karpiński TM. Curcumin, a natural antimicrobial agent with strain-specific activity. Pharmaceuticals. 2020 Jul;13(7):153

[23] Talón E, Lampi AM, Vargas M, Chiralt A, Jouppila K, González-Martínez C. Encapsulation of eugenol by spraydrying using whey protein isolate or lecithin: Release kinetics, antioxidant and antimicrobial properties. Food chemistry. 2019 Oct 15;295:588-98.

[24] Marchese A, Barbieri R, Coppo E, Orhan IE, Daglia M, Nabavi SF, Izadi M, Abdollahi M, Nabavi SM, Ajami M. Antimicrobial activity of eugenol and essential oils containing eugenol: A mechanistic viewpoint. Critical reviews in microbiology. 2017 Nov 2;43(6):668-89. 